\title{
Cuprous Phenanthroline MLCT Chromophore Featuring Synthetically Tailored Photophysics
}

Sofia Garakyaraghi, Peter D. Crapps, Catherine E. McCusker, Felix N. Castellano*

\section{Supporting Information}

Calculating rate constants for nonradiative and radiative decay.

The radiative rate $\left(k_{r}\right)$ constants were calculated using $\Phi$ and $\tau$ (Table 1) using Eq. S3.

$$
\begin{array}{ll}
\phi=\frac{k_{r}}{k_{n r}+k_{r}} & \text { Eq.S1 } \\
\tau=\frac{1}{k_{n r}+k_{r}} & \text { Eq.S2 }
\end{array}
$$

Combining and rearranging Eq. S1 and Eq. S2 gives:

$$
k_{r}=\frac{\phi}{\tau} \quad \text { Eq. S3 }
$$

The nonradiative rate $\left(k_{n r}\right)$ constants were calculated using Eq. S1 and Eq. S3. 


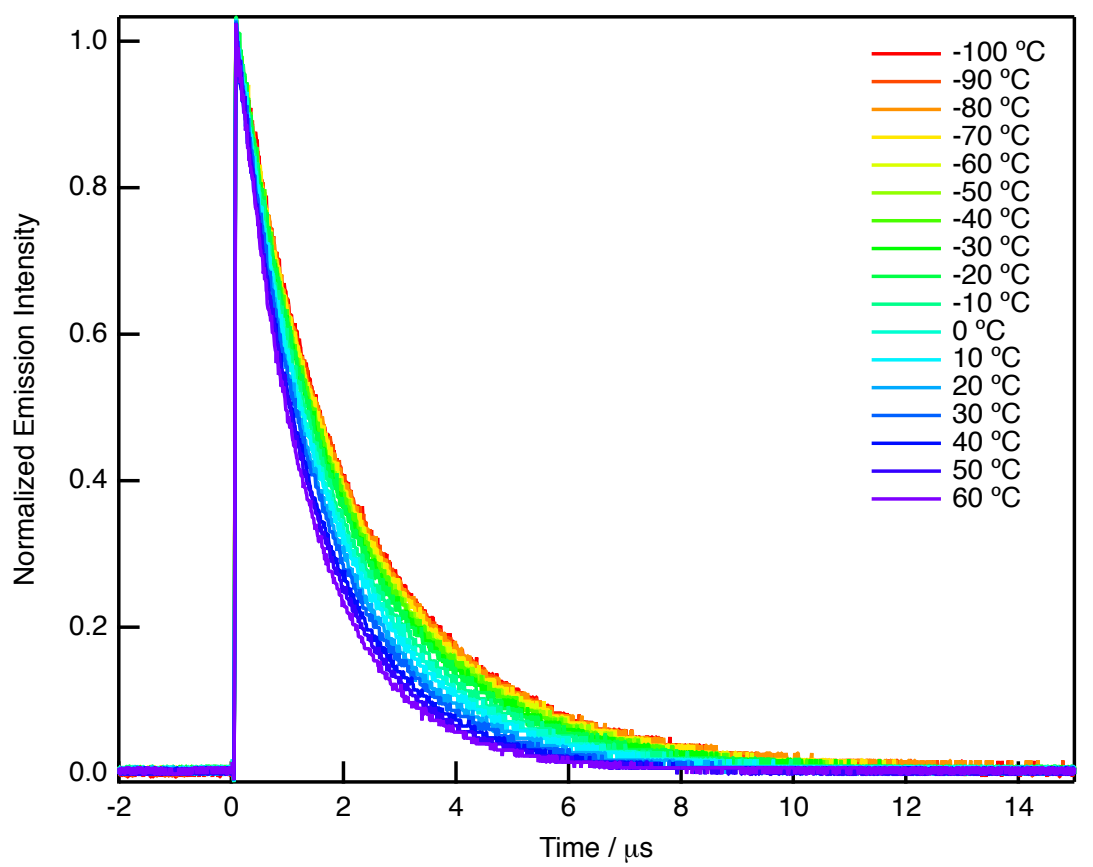

Figure S1. Normalized variable temperature emission decays of $\left[\mathrm{Cu}(\operatorname{diptmp})_{2}\right]^{+}$in deaerated THF with temperatures indicated in the legend.

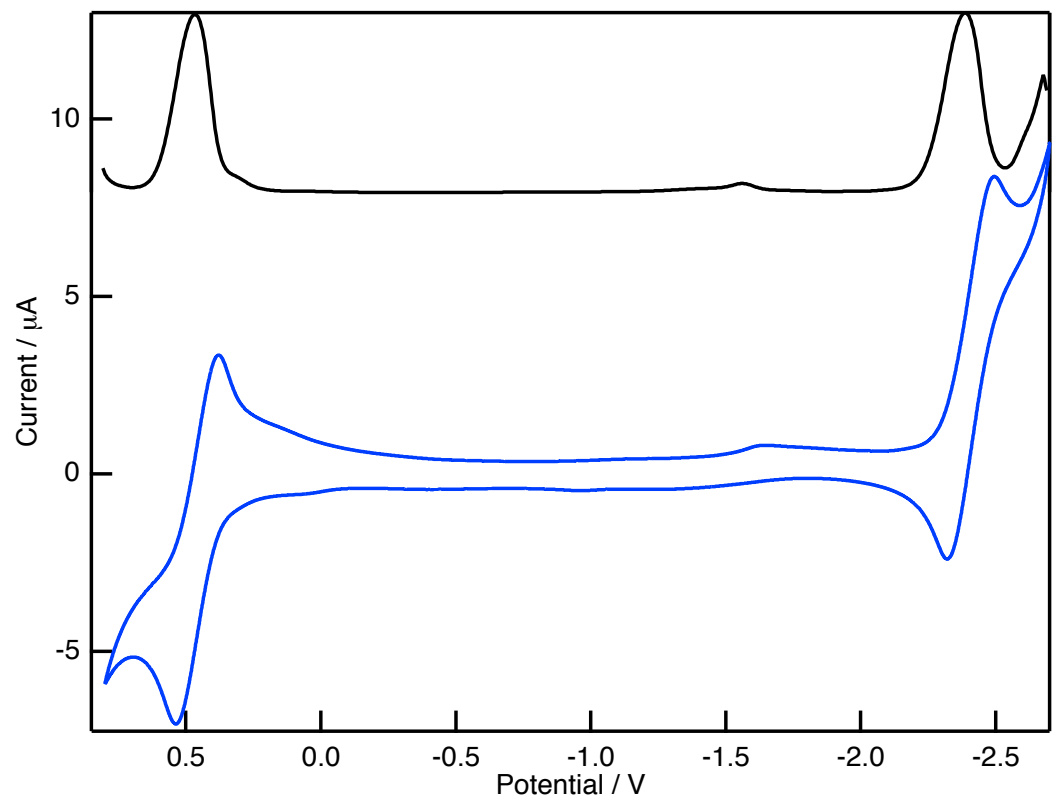

Figure S2. Cyclic voltammetry (blue) and differential pulse voltammetry (black) spectra for $\left[\mathrm{Cu}(\text { diptmp })_{2}\right]\left(\mathrm{PF}_{6}\right)$ in THF solution with $0.1 \mathrm{M} \mathrm{TBAPF}_{6}$ as the supporting electrolyte. Potentials were measured vs. the $\mathrm{Ag} / \mathrm{AgNO}_{3}$ and all potentials are reported vs. the $\mathrm{Fc}^{+/ 0}$ redox couple, which was used as an internal standard. 


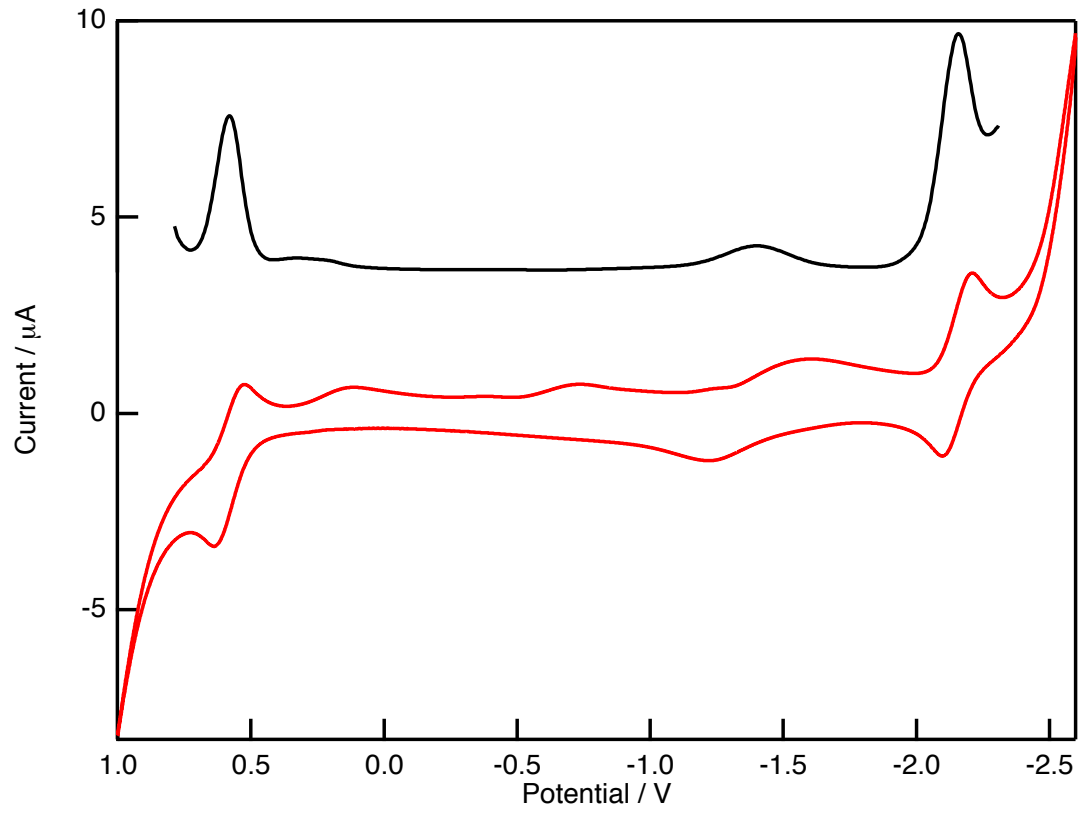

Figure S3. Cyclic voltammetry (red) and differential pulse voltammetry (black) spectra for $\left[\mathrm{Cu}(\text { dipp })_{2}\right]\left(\mathrm{PF}_{6}\right)$ in THF solution with $0.1 \mathrm{M} \mathrm{TBAPF}_{6}$ as the supporting electrolyte. Potentials were measured vs. the $\mathrm{Ag} / \mathrm{AgNO}_{3}$ and all potentials are reported vs. the $\mathrm{Fc}^{+/ 0}$ redox couple, which was used as an internal standard.

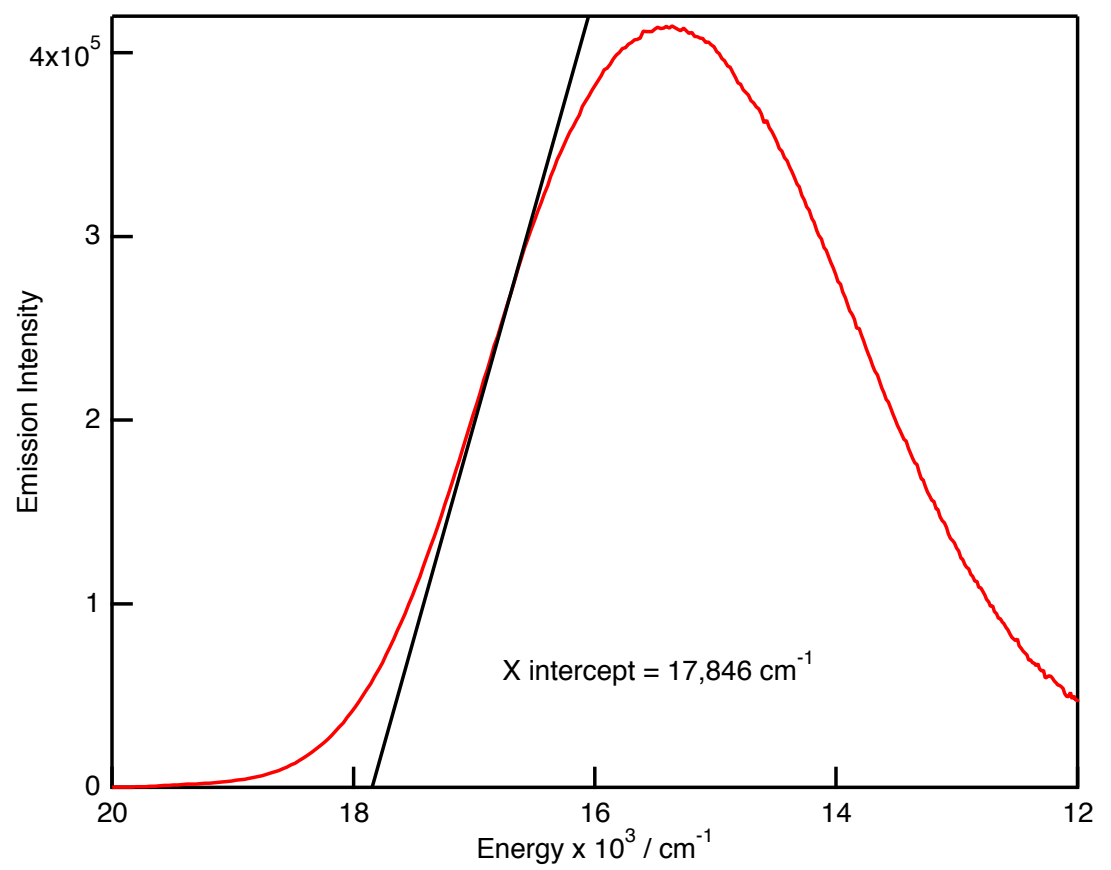

Figure S4. Emission of $\left[\mathrm{Cu}(\mathrm{diptmp})_{2}\right]^{+}$in THF solution, corrected with the Parker-Rees correction ${ }^{1}$ to convert to an energy scale. Black line is a tangent to the high-energy emission edge, where the $\mathrm{X}$ intercept is approximately $\mathrm{E}_{00}$. 


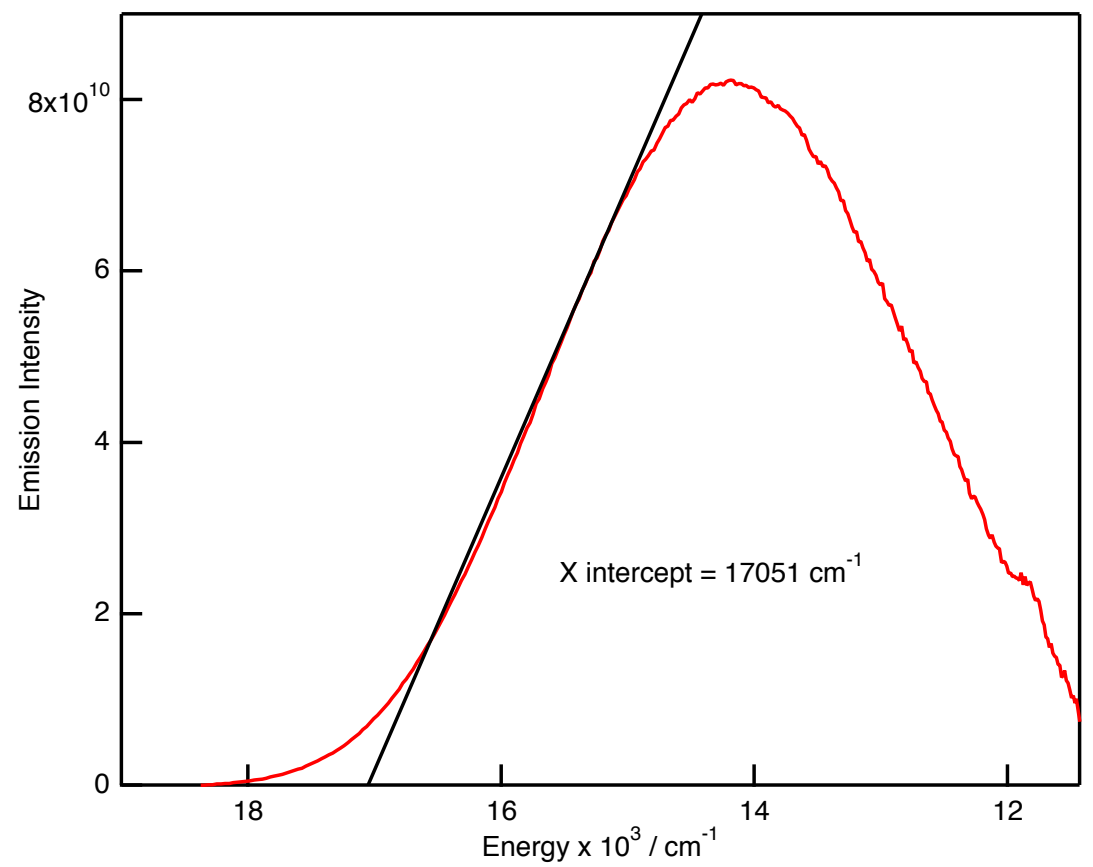

Figure S5. Emission of $\left[\mathrm{Cu}(\mathrm{dipp})_{2}\right]^{+}$in THF solution, corrected with the Parker-Rees correction ${ }^{1}$ to convert to an energy scale. Black line is a tangent to the high-energy emission edge, where the $\mathrm{X}$ intercept is approximately $\mathrm{E}_{00}$. 

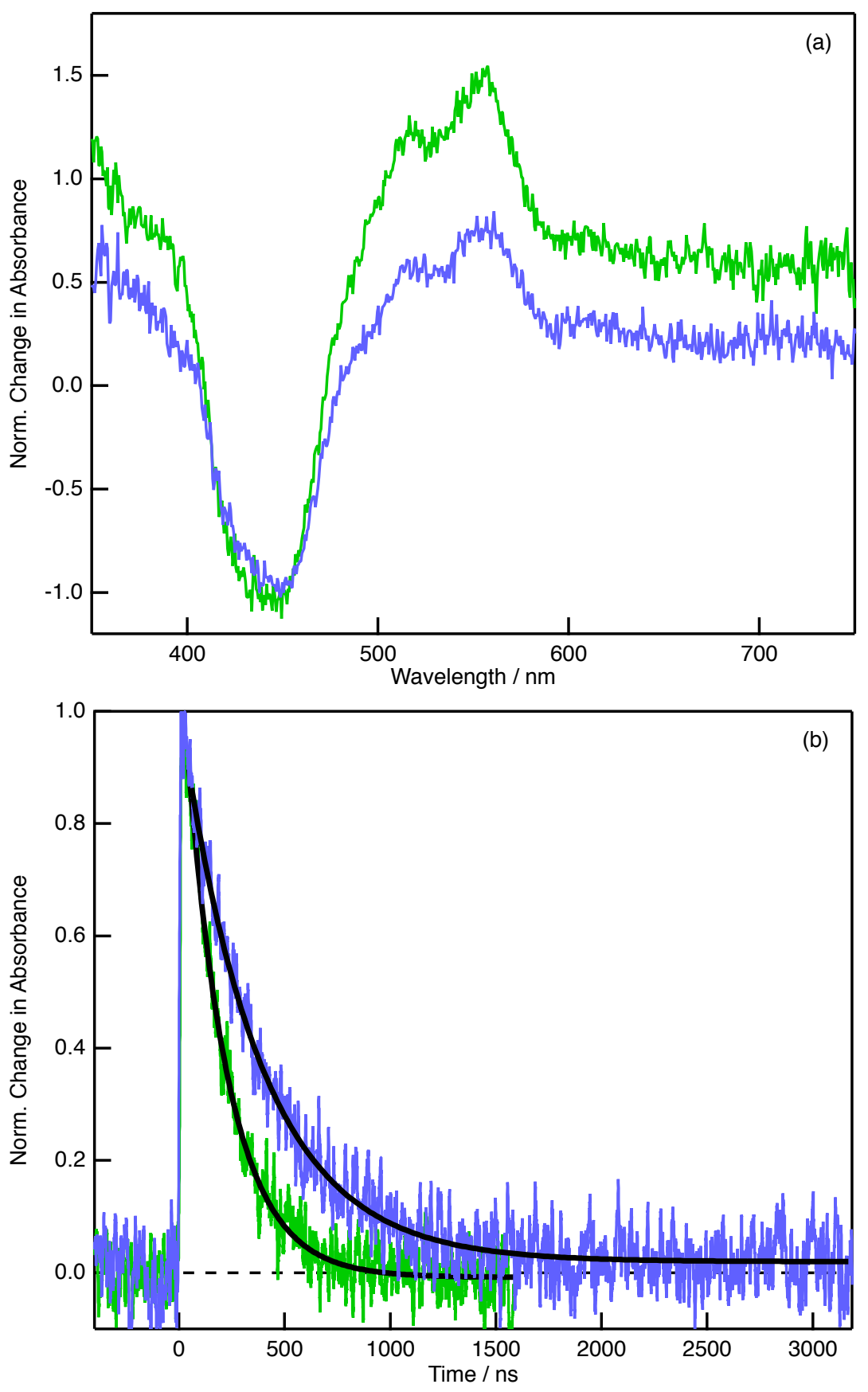

Figure S6. (a) The prompt differential nanosecond transient absorption spectra of $\left[\mathrm{Cu}(\mathrm{dipp})_{2}\right]^{+}$in deaerated $\mathrm{CH}_{2} \mathrm{Cl}_{2}$ (blue) and THF (green) solutions after $450 \mathrm{~nm}$ excitation. (b) Transient absorption decay kinetics of $\left[\mathrm{Cu}(\text { dipp })_{2}\right]^{+}$in deaerated $\mathrm{CH}_{2} \mathrm{Cl}_{2}$ (blue) and THF (green) solutions probed at $550 \mathrm{~nm}$. Black lines are the result of single exponential fits yielding lifetimes summarized in Table 1. 

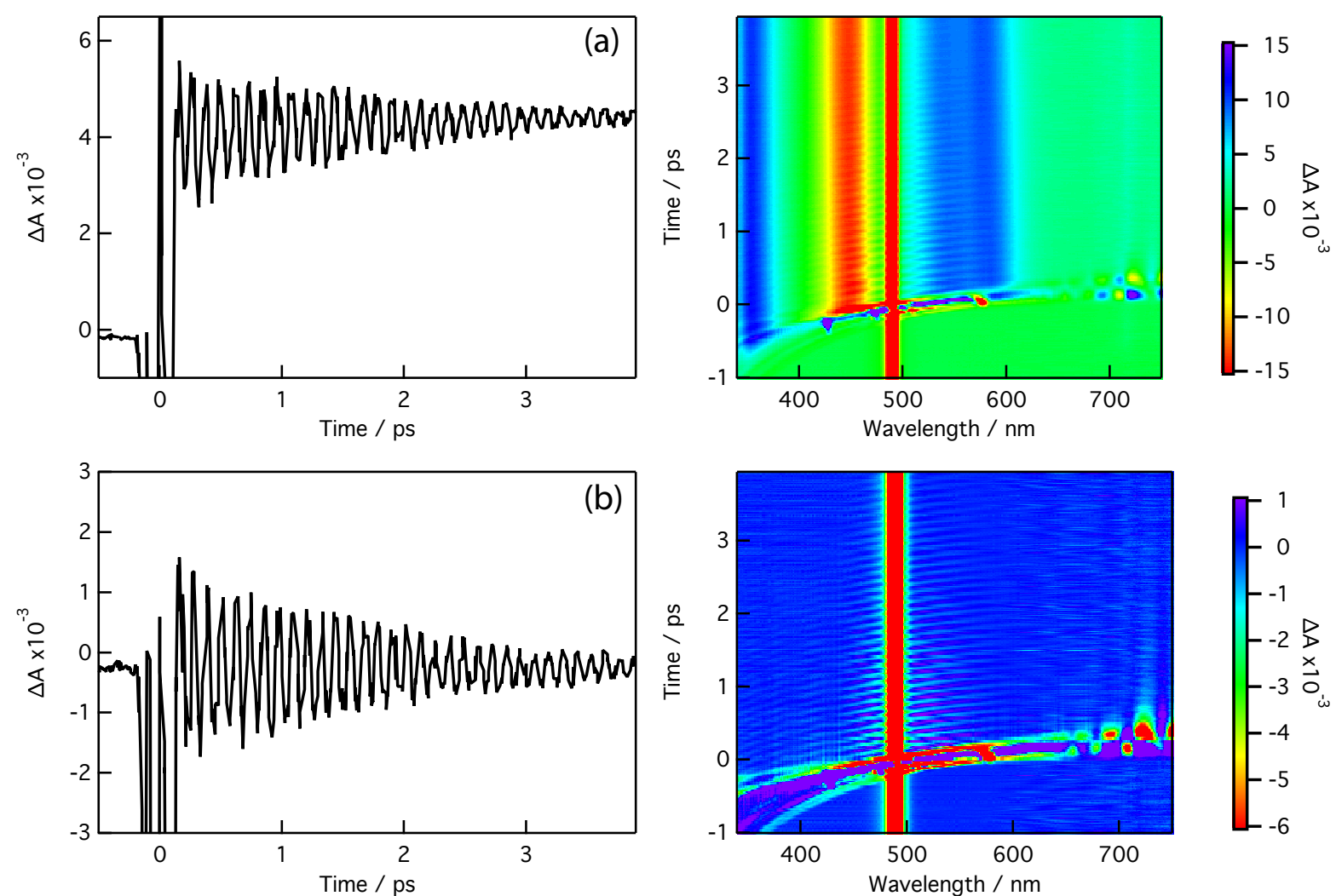

Figure S7. Transient absorption kinetics $\left(\lambda_{\text {probe }}=508 \mathrm{~nm}\right)$ and surface plot of $(\mathbf{a}) \mathrm{Cu}(\operatorname{diptmp})_{2}{ }^{+}$in dichloromethane and (b) solvent blank performed with dichloromethane reveal impulsive stimulated Raman scattering artifacts that persist for several picoseconds following $470 \mathrm{~nm}$ pulsed excitation $(2.0 \mathrm{uJ}$ per pulse, $100 \mathrm{fs}$ fwhm). These artifacts appear as oscillatory signals and can be visualized in the surface plot as fringes. 


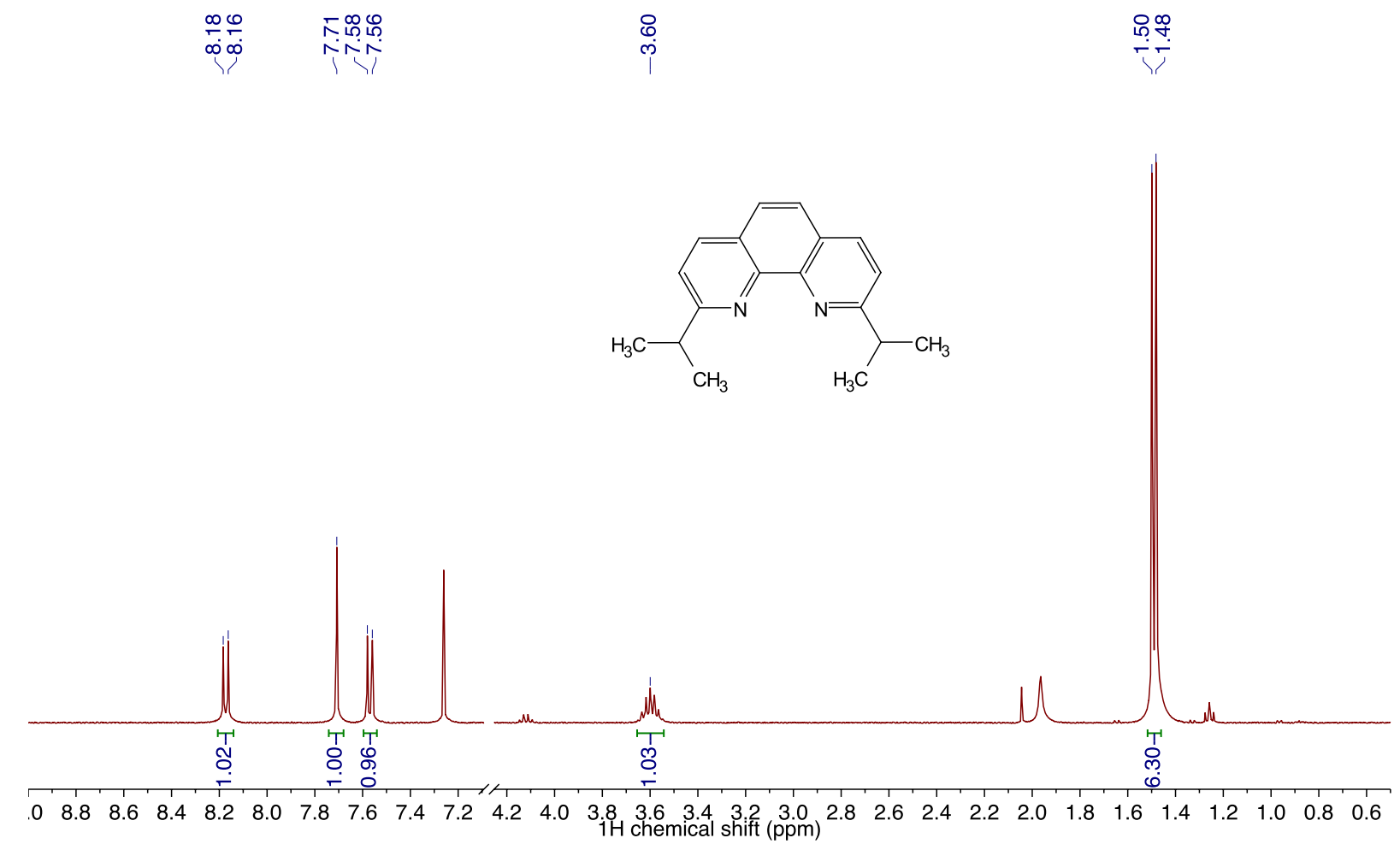

Figure S8. ${ }^{1} \mathrm{H}$ NMR spectrum of dipp in $\mathrm{CDCl}_{3}$
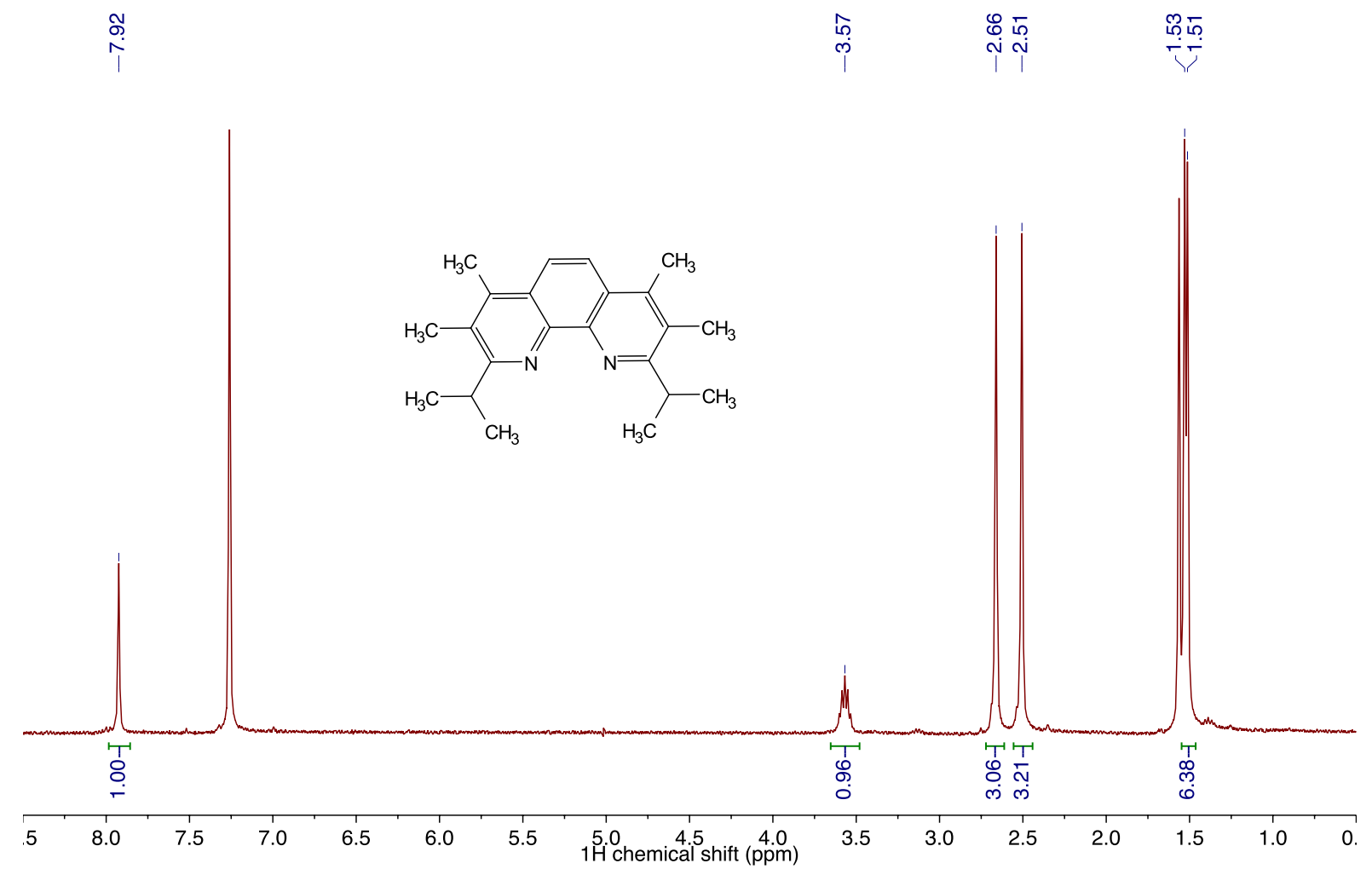

Figure S9. ${ }^{1} \mathrm{H}$ NMR spectrum of diptmp in $\mathrm{CDCl}_{3}$ 


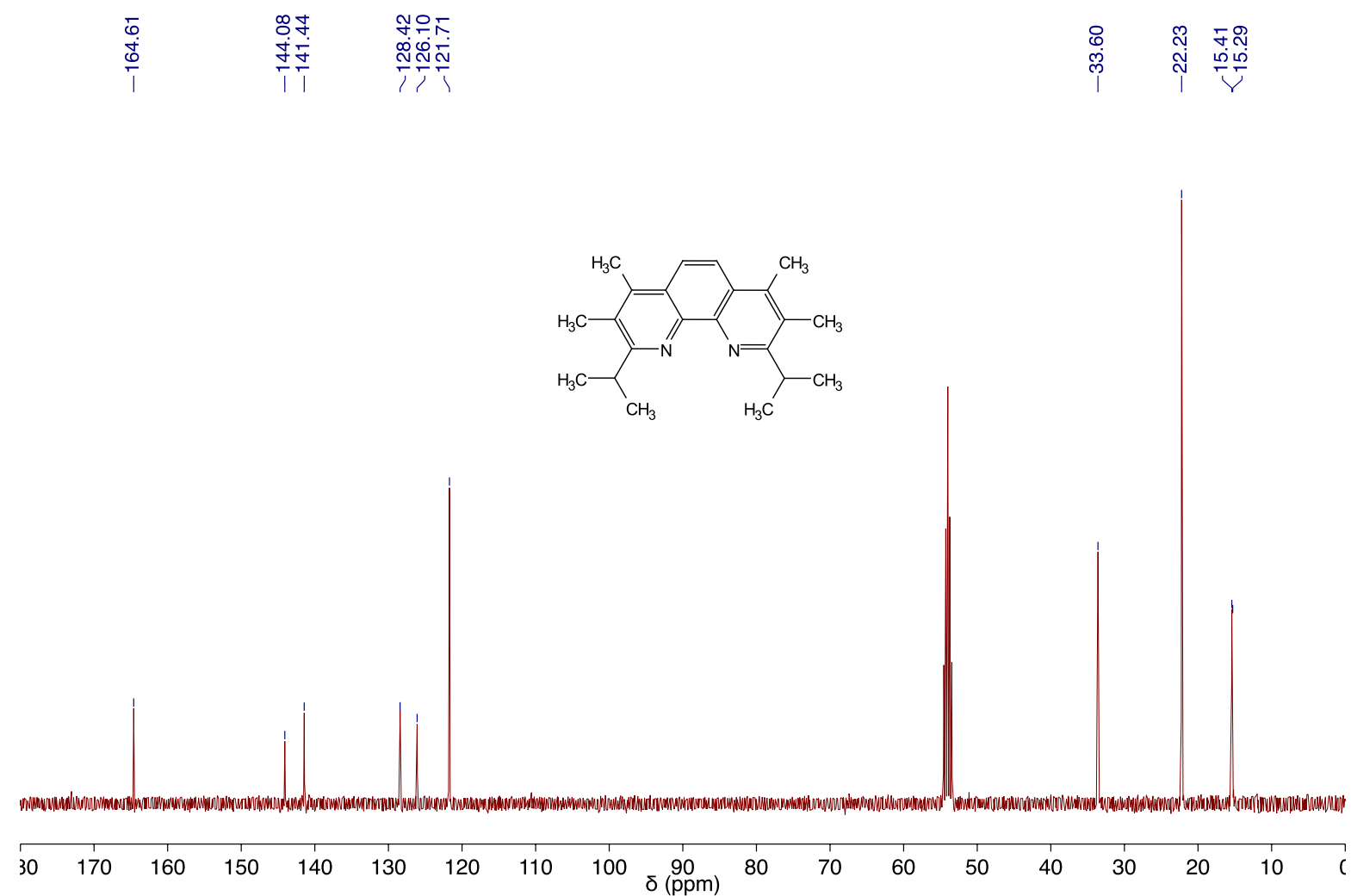

Figure S10. ${ }^{13} \mathrm{C}$ NMR spectrum of diptmp in $\mathrm{CDCl}_{3}$

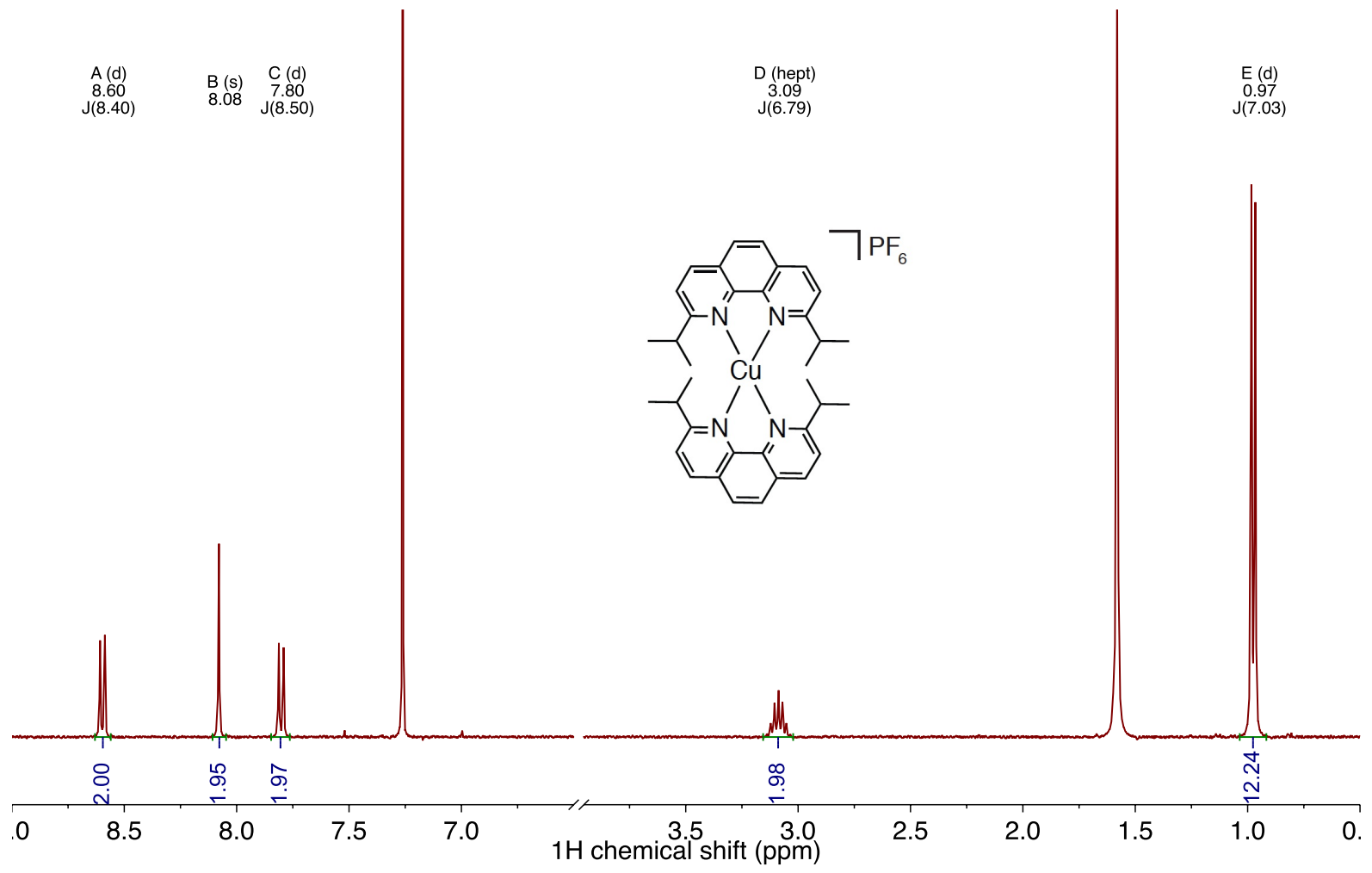

Figure S11. ${ }^{1} \mathrm{H}$ NMR spectrum of $\left[\mathrm{Cu}(\operatorname{dipp})_{2}\right]\left(\mathrm{PF}_{6}\right)$ in $\mathrm{CDCl}_{3}$ 


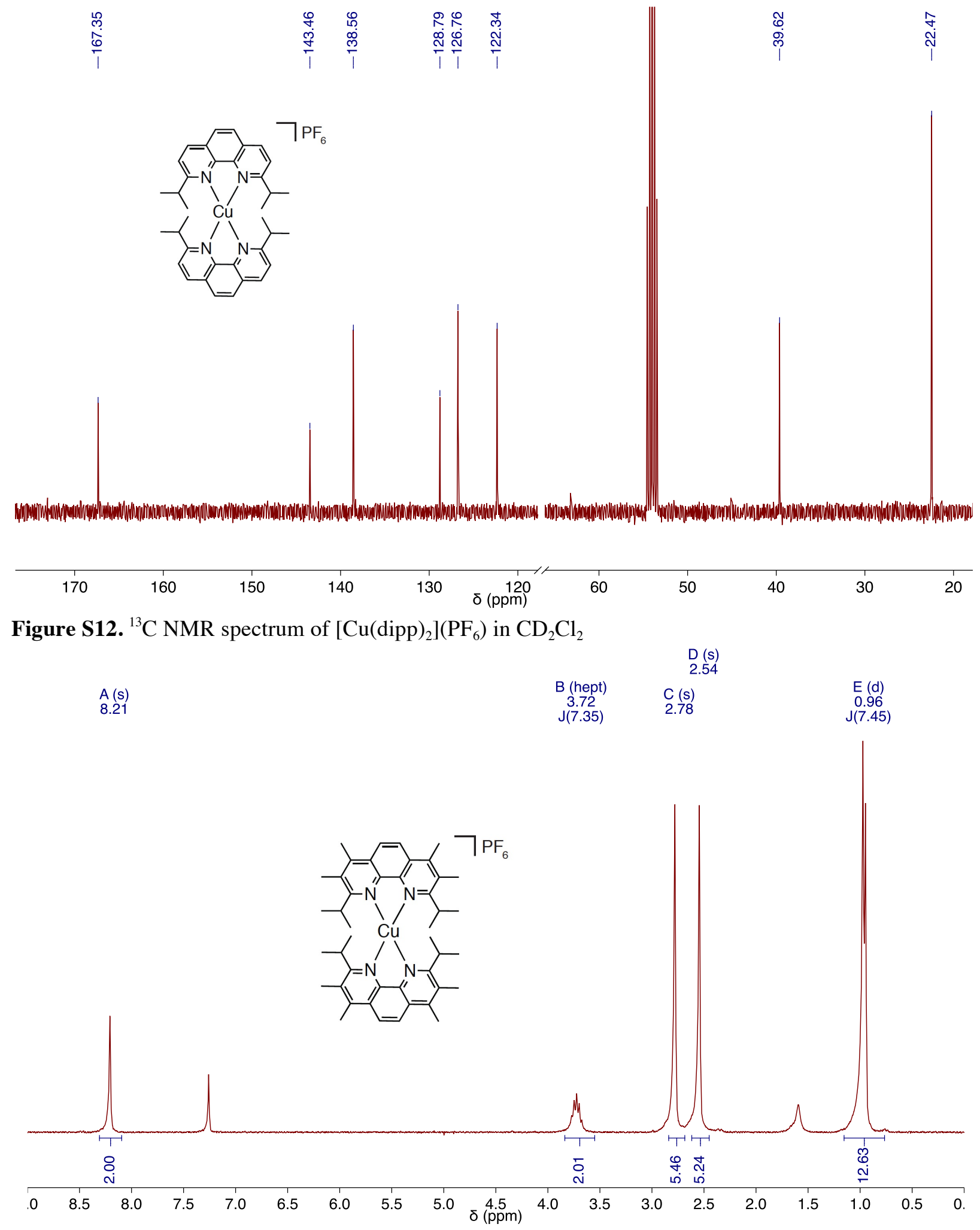

Figure S13. ${ }^{1} \mathrm{H} \mathrm{NMR}$ spectrum of $\left[\mathrm{Cu}(\operatorname{diptmp})_{2}\right]\left(\mathrm{PF}_{6}\right)$ in $\mathrm{CDCl}_{3}$ 


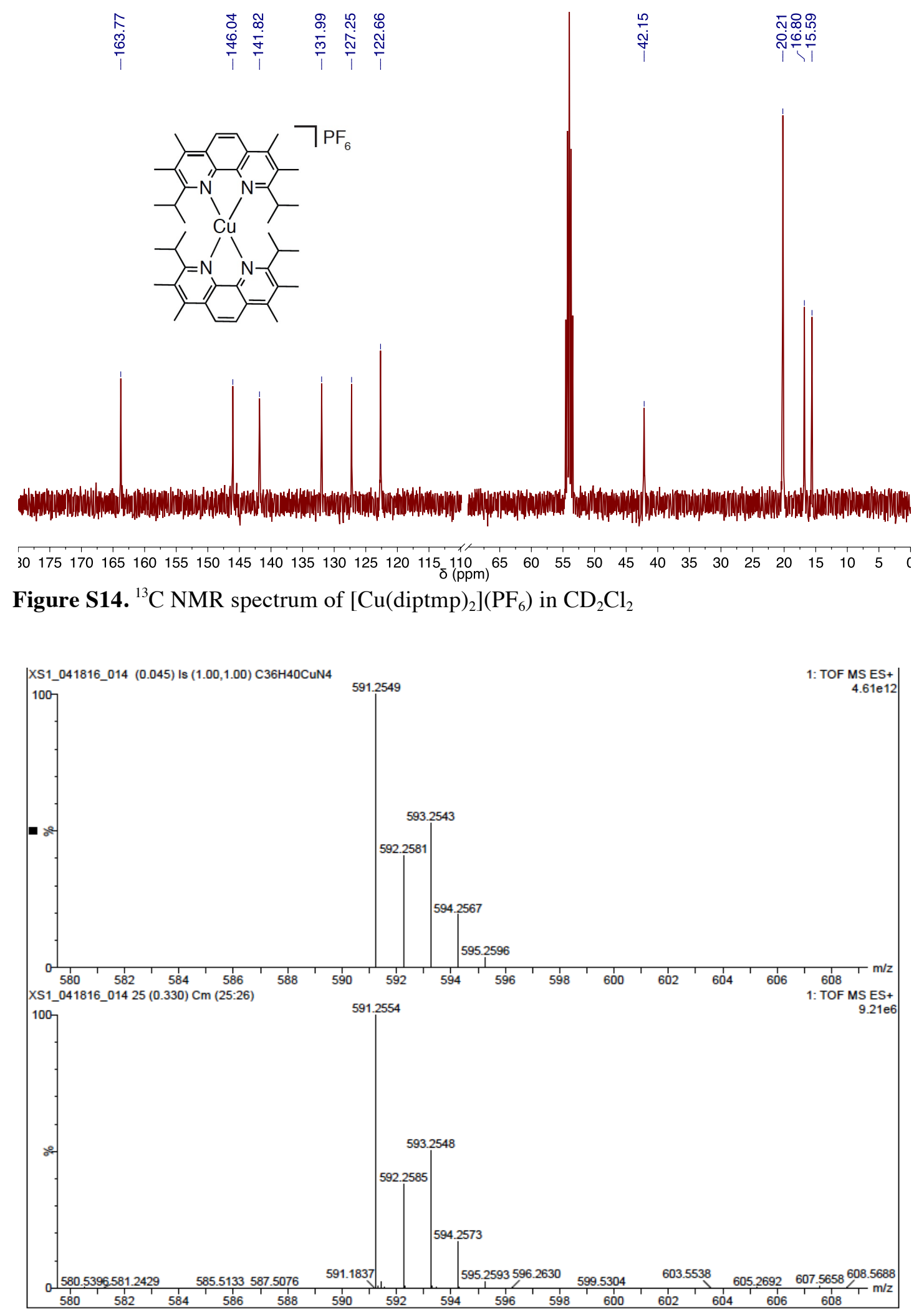

Figure S15. Mass spectra showing the theoretical (top) and measured (bottom) isotope pattern for the [M$\left.\mathrm{PF}_{6}\right]^{+}$ion of $\left[\mathrm{Cu}(\operatorname{dipp})_{2}\right]\left(\mathrm{PF}_{6}\right)$ 


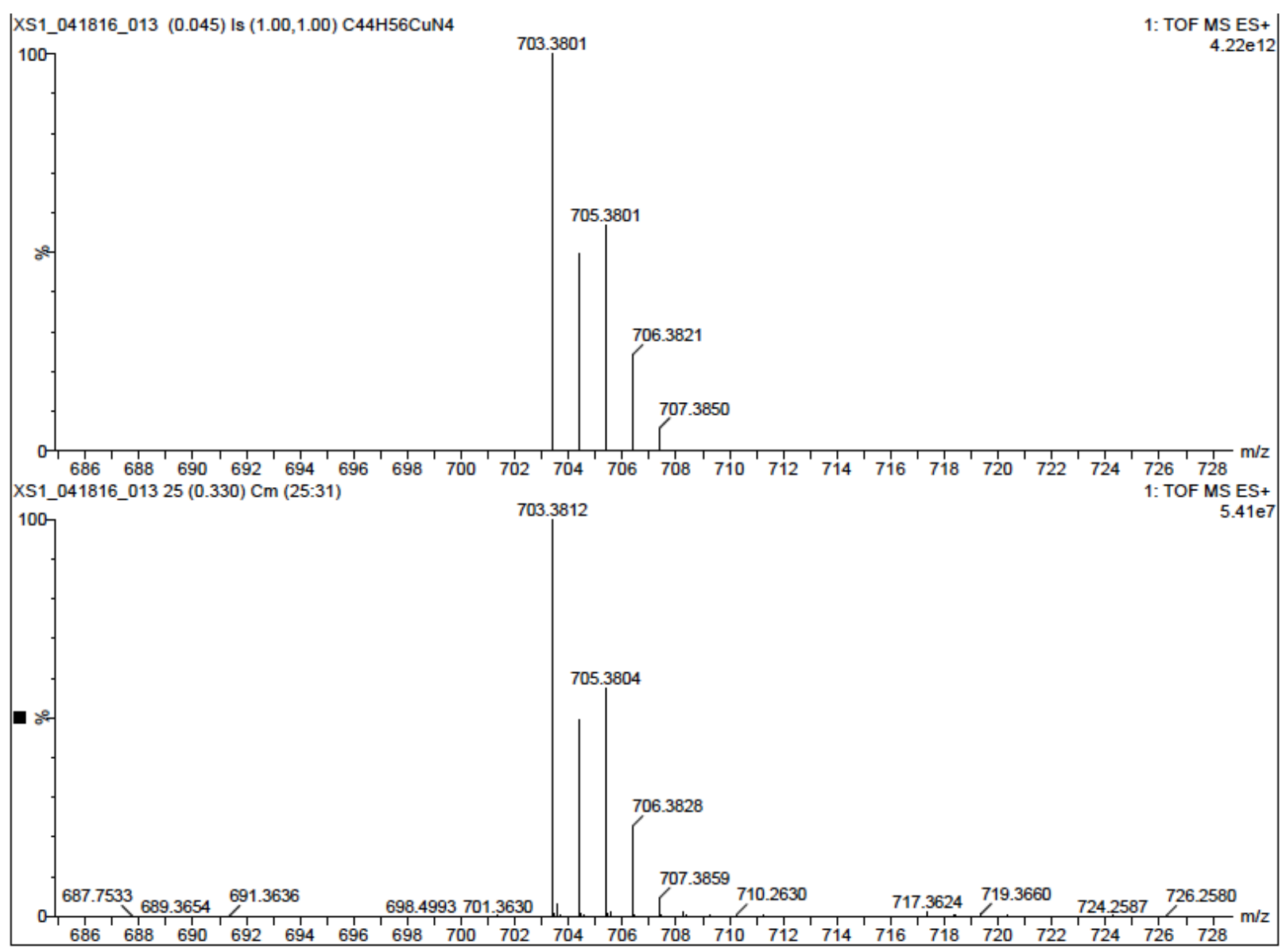

Figure S16. Mass spectra showing the theoretical (top) and measured (bottom) isotope pattern for the [M$\left.\mathrm{PF}_{6}\right]^{+}$ion of $\left[\mathrm{Cu}(\operatorname{diptmp})_{2}\right]\left(\mathrm{PF}_{6}\right)$

\section{Reference.}

1. Parker, C. A.; Rees, W. T. Analyst 1960, 85, 587-600. 